\title{
The Relationship between Traditional Mass Media and "Social Media": Reality Television as a Model for Social Network Site Behavior
}

\section{Michael A. Stefanone, Derek Lackaff, and Devan Rosen}

Social cognitive theory suggests a likely relationship between behavior modeled on increasingly popular reality television (RTV) and user behavior modeled on social networking sites (SNSS). This study surveyed young adults ( $N=$ 456) to determine the extent to which RTV consumption explained a range of user behavior in the context of social network sites. Results show a consistent relationship between RTV consumption and the length of time spent on these sites, the size of users' networks, the proportion of friends not actually met face to face, and photo sharing frequency while controlling for age and gender.

In the now-classic work Life on the Screen, sociologist Turkle (1995) effectively captured the radical zeitgeist of the early public Internet: absent physical cues in the text-based medium, individuals free to construct and deconstruct identity as they saw fit. Gender, race, and ability only became a component of social exchange to the degree that individuals chose to introduce it. Significant amounts of subsequent research energy were devoted to exploring how computer mediation affects personal identity construction and social interaction (e.g., Ellison, Heino, \& Gibbs, 2006; Walther, 2007).

A key challenge to such efforts is the fact that the quantity and quality of nonverbal (or nontextual) social cues available to computer-mediated communication (CMC) participants changed continuously since scholars first began examining them. Rather than allowing users to experiment and play with their identity, many of today's CMC technologies tie users ever closer to their offline, physical selves. As

Michael A. Stefanone (Ph.D., Cornell University) is an assistant professor in the Department of Communication at the State University of New York at Buffalo. His research interests include group-level computermediated communication, distributed groups and Internet-based communication tools like social networking sites.

Derek Lackaff (Ph.D., SUNY Buffalo) is a postdoctoral fellow in the Department of Radio-Television-Film at the University of Texas at Austin. His research interests include social media, social networks, and digital media economics.

Devan Rosen (Ph.D., Cornell University) is an assistant professor in the Department of Speech at the University of Hawaii at Manoa. His research interests include communication technologies and social network analysis. 
new communication platforms diffuse throughout a population, navigating a social environment comprised of mediated identities becomes an increasingly important communication skill.

In some regards, contemporary societies were long accustomed to interacting with completely "mediated" identities. Although relatively few Americans have any direct interpersonal interaction with Britney Spears, Brad Pitt, or Kelly Clarkson, many could claim intimate knowledge of these individuals' daily lives. Many people may see photos of Gisele Bündchen and Heidi Klum more frequently than photos of distant friends or family members. Further, celebrity fans use communication technologies to interact with their idols in many new ways. Manhattanites, for example, plot celebrity "sightings" on the online map available at Gawker Stalker (http://gawker.com/stalker).

Celebrity of the type enjoyed or endured by actors, models, and athletes, was both a consequence and generator of the mass audience, and resulted in an informational flow that primarily was unidirectional. While celebrity was something that mass audiences were encouraged to aspire to (McCraken, 1989), the world of celebrities was fundamentally removed from that of the audience. The authors argue that the normative and behavioral distinction between the celebrity world and the everyday world eroded, and that the dissolution of this boundary is observable in two distinct trends: the development and explosive popularity of so-called "reality television" (RTV), and the concomitant adoption of "Web 2.0" technologies like social networking sites ( $\mathrm{SNSs}$ ) that allow individuals to be identified by and communicate with mass-scale audiences.

RTV is a dominating component of the contemporary television environment. It focuses on the (purportedly) unscripted interaction of nonprofessional actors often framed as "ordinary people" (Reiss \& Wiltz, 2004). The transformation of "regular people" into "celebrities" whose every move is worthy of a mass audience's attention was a powerful concept. While the specific components of RTV shows vary, it is possible to identify broad generic values of RTV programming content. For example, actors regularly engage in "confessions" where they ritualistically disclose their private thoughts and feelings to the broadcast audience. Blogs and other easily accessible communication platforms (the so-called "Web 2.0"; O'Reilly, 2005) have likewise enabled a growing number of Internet users to publish their thoughts, photos, and videos on the Web (Stefanone \& Jang, 2007).

Taken together, RTV and Web 2.0 set the stage for a major shift in the way individuals perceive their role in the contemporary media environment. Rather than simply being targeted by mediated messages, they can see themselves as protagonists of mediated narratives who actively integrate themselves into a complex media ecosystem. The media tools and strategies employed by celebrities and their handlers-airbrushed photos, carefully coordinated social interactions, strategic selection, and entourage maintenance-are now in a sense available to everyone, and increasingly are employed in everyday interpersonal interaction. Today, much CMC thus is marked by an increasing emphasis on existing offline relationships, physical and nonverbal communication cues, and their manipulation. 
In this article, Bandura's social cognitive theory (Bandura, 2001; Bandura \& Walters, 1977) frames an analysis of the relationship between RTV consumption and online behavior with Web 2.0 tools like SNSs. Viewers are operationalized as active processors of television content who learn and model behavior portrayed in television programming. Five broad categories of television viewing are analyzed and used to predict a range of SNS user behaviors. Results suggest that social behaviors commonly associated with celebrities are now enacted by non-celebrities in an increasingly mediated social environment. The following review frames the study as follows. First, reality television programming presents a consistent set of values and behaviors related to self-disclosure. Second, the development of social media platforms enables non-media professionals, or "normal people" to participate in a newly accessible media environment, not just as an audience member, but also as multimedia producers. Finally, social cognitive theory provides a potential framework for linking the consumption of "reality" culture with specific media production behaviors.

\section{Literature Review}

\section{Reality Television and Affect TV}

The relationship between mass media content and cultural attitudes is among the most-examined issues in mass communication research. Previous studies explored the impacts of mass media upon attitudes towards violence (Dominick, 1984), sex (McGee \& Frueh, 1980), and smoking (Shanahan, Scheufele, Yang and Hizi, 2004), among many additional topics. One content trend observed in the last two decades is the relative increase of reality-framed television programming. RTV makes the personal thoughts, behaviors, and interactions of its characters the main focus of audience attention. Bente and Feist refer to this genre as affect $T V$, which presents viewers with "the most private stories of non-prominent people to a mass audience, crossing traditional borders of privacy and intimacy" (2000, p. 114). Recently, Ferris, Smith, Greenberg, and Smith (2007) conducted a content analysis of reality dating television and observed that watching these shows related to perceptions of dating relationships consistent with those modeled on television. As in the current study, Ferris and colleagues used social cognitive theory to explain the connection between television viewing and subsequent attitudes. The current study, however, differs in that RTV is conceptualized more broadly as described below.

Calvert (2000) refers to RTV's realignment of the private and the public as mediated voyeurism and suggests that this is becoming endemic to the culture at large. This culture of mediated voyeurism may have a real impact on those most involved in it. Previous research suggests that the symbolic world portrayed in the media (particularly television) may differ from the real world in important ways - the televised world is more violent (Gerbner, Gross, Morgan, \& Signorielli, 1980), more 
youthful (Gerbner, Gross, Signorielli, \& Morgan, 1980), offers employment that is high-status but requires low effort (Signorelli, 1990), and over-represents traditional gender roles and stereotypes (Morgan, 1982; Rothschild, 1984). The cultivation perspective of media effects (Gerbner, Gross, Morgan, \& Signorelli, 1986; Shanahan \& Morgan, 1999) suggests that television viewers attempt to align their attitudes and beliefs with those observed in television programming. Cultivation theory was criticized, however, for being overly broad and unable to account for underlying contextual factors of attitude formation (Rubin, Perse, \& Taylor, 1988; Shanahan \& Morgan, 1999), and insufficient methodological rigor (Shrum, 2007). Bandura's (1986) social cognitive theory allows for the integration of social contextual factors into the effects model, and provides a useful framework for discussing the effects of celebrity culture and mediated voyeurism.

\section{Web 2.0}

Recent studies indicate that younger people are increasingly engaged with social technologies. Over half of all Internet-using teens are "content creators" who create websites or blogs, share original media such as photos and videos, or remix content into new creations (Lenhart \& Madden, 2005). SNSs such as MySpace (http://myspace.com) and Facebook (http://facebook.com) often are a cornerstone of this information space, with many recent surveys reporting that $95 \%$ or more of college students have active profiles (e.g., PACS survey, 2007).

There appears to be substantial congruence between Web 2.0's culture of personal self-disclosure and the "reality culture" that dominates some segments of the television market. Recent research on blogging, for example, operationalizes disclosures via personal-journal style blogs as non-directed in nature (Stefanone \& Jang, 2007), analogous to behavior typified by the RTV genre wherein characters engage in "confessional" style disclosures to view. In the current article, two social web behaviors that enable individuals to emulate mediated celebrity are discussed: SNS use and digital photo sharing.

\section{Social Network Sites}

The explosion in popularity of SNSs represents one of the fastest uptakes of a communication technology since the web was developed in the early 1990s. As of March 2009, 2 of the Top 10 most popular websites worldwide were SNSs (Facebook and Myspace; Alexa Top Sites, http://alexa.com). Academic research on SNSs is growing, with focus on a range of issues including privacy (Gross, Acquisti, \& Heinz, 2005), identity and reputation (boyd \& Heer, 2006; Walther, Van Der Heide, Kim, Westerman, \& Tong, 2008), and the role these sites play in relationship maintenance and the accumulation of resources like social capital (Choi, 2006; Ellison, Steinfeld, \& Lampe, 2007). These sites typically allow an individual to connect her/his personal profile to the profiles of other users, resulting 
in a public display of one's entire (online) social network. On a technical level, becoming a "friend" requires only a few clicks of the mouse, rather than any investment in conversation or social support. This results in a diversity of approaches to understanding SNS "friendship."

A host of web services such as Flickr (http://flickr.com) and Snapfish (http://snap fish.com) emerged to support storage, organization, and sharing digital photos, while general social networking sites such as Facebook and MySpace include photosharing as a key functionality. Miller and Edwards (2007) note that two relatively distinct modes of photo sharing can be observed online-both the traditional sharing of photos with an existing social network of friends and family, and an emergent form of public sharing with strangers and online acquaintances. These two groups are perhaps better understood as representing ends of a spectrum of sharing behaviors, as the boundaries of intimacy increasingly are blurred by technological affordances. However, it is reasonable to assume that a primary goal of digital photo sharing, like analog photo sharing, is the development and maintenance of interpersonal relationships.

\section{Social Cognitive Theory}

People's adoption and use of Internet-based communication tools were studied from a wide range of perspectives. Social cognitive theory-formerly social learning theory (Bandura, 1986) - attempts to explain how and why people acquire and maintain certain behavioral patterns. Human functioning is explained as the product of dynamic interaction of personal, behavioral, and environmental influences. Personal influences include cognitive, affective, and biological factors. Environmental factors include social context and the informational environment. Finally, Bandura includes behavior as a component of function because individuals can reflect on the effects of their own behavior. This tripartite construct thus is dynamic and highly contextual.

Social cognitive theory uses the term modeling to characterize the process through which individuals observe others, interpret their behavior, and adjust their own behavior in response. Such observational learning may be the intended outcome of a given behavioral process, such as teaching a child to feed itself. However, Bandura (1986) notes that modeling may occur in many other contexts, indeed wherever an individual is able to observe others' behavior. The development of television is viewed by Bandura as an especially important source of behavior models, enabling people to "transcend the bounds of their immediate social life" (1986, p. 55). In comparison to the quantity of information about the world available in daily life, the amount of environmental information provided via media is vast. To the extent that one's images of reality are mediated and vicarious rather than directly experiential and experimental, the greater is the impact of the media (Bandura, 1986). Bandura is careful to show that modeling is a more complex process than simple mimicry or imitation, and identifies several specific functions of the process. 
The observational learning process requires a model, a learnable attitude or behavior, and a conducive personal/behavioral/environmental context. In the present study, the characters in RTV programming serve as models, and the Web 2.0 environment provides a new context for enacting observed behavior. The wide adoption of platforms such as SNSs among the largest demographic of RTV viewers-young adults (Hill, 2005)—suggests significant potential for interrelated media behavior.

As RTV programming is considered a coherent genre, its characters may serve as symbolic models for behavior. While previous discussions of the genre included shows such as COPS, where some participants (the "suspects") are ostensibly unwilling, this discussion is limited to socially rewarding RTV with participants who willingly disclose their private selves.

One of RTV's strongest messages regards non-directed self-disclosure, where personal revelations are not targeted toward specific, individual others, but rather targeted to an abstract audience. As the personal thoughts of the characters are not (yet) directly accessible to the viewing audience, the narrative structure of many RTV shows requires the characters to transgress traditional boundaries of privacy, a sacrifice they are happy to make. Characters are subject to high levels of surveillance, and often are required to present their motivations and private thoughts to a camera in the format of confessionals, interviews, etc. These high levels of surveillance and disclosure are presented as necessary and fundamentally normal. RTV participants are rewarded for this behavior with celebrity status and financial gain in the form of prize money.

According to social cognitive theory, a production process is the enactment of an observed behavior, while a motivation process refers to the fact that the enactment of any behavior is subject to contextual incentives and disincentives. These two sub-processes of the observational learning process will be discussed in tandem as they are related to the emergence of Web 2.0 technologies.

SNSs provide a unique platform for the reproduction of behavior observed in and modeled by RTV programming. For most of their history, "the media" were the domain of those who were, by definition, celebrities. With the wide scale adoption of media sharing, blogging, and SNSs, a much broader range of people now have the capability of creating mediated identities. The creation of an SNS profile allows a user to become a mediated character to others. While probably few SNS users would compare their Facebook profile to a talk-show appearance by a movie star, the SNS platform both enables and encourages activities traditionally associated with celebrity, such as the primacy of image and appearance in social interaction.

One behavior which may result from RTV modeling is promiscuous friending. While many users articulated SNSs that map closely to their own external social networks, other users have SNS friend networks that contain many people whom they have not met or with whom they have no external relationship. Promiscuous frienders may be reproducing the fame-seeking behavior that is modeled by RTV characters. Having a large social network on a SNS site can be construed as a sign of popularity (being at the center of a large social network), and conversely as a sign of superficiality (e.g., a "whore," [boyd, 2006] who is a blatant status-seeker). 
In either case, a large "friends" list implies a large number of social connections, even if many of those connections have limited social value in the traditional sense of friendship.

Bandura (1986) recognized that not all observed behaviors ultimately are reproduced, and attributes this to motivational processes. The capacity to enact a behavior is insufficient grounds for most people to do so. Motivational processes like positive anticipated outcomes must be entered into the equation. Once again, RTV provides plentiful motivational input. Within the genre of socially rewarding RTV, participants are rewarded with celebrity and cash prizes for their participation. Consistent with Calvert (2000), the authors suggest the RTV genre demonstrates a value system which equates celebrity status and fame with social prestige and personal value. Further, RTV demonstrates that anyone can become a public celebrity-special talents, looks, skills, or wealth not required. The development of powerful, accessible tools for self-expression-the platforms of Web 2.0-make it possible for individuals to "mediate" themselves, and reach audiences on the same scale as movie stars and fashion models. Taken together, these trends suggest both motivations and predictable outcomes for online behavior.

For example, heavy RTV viewers exposed to consistent models about the benefits of celebrity culture likely spend more time online managing their mediated identities and are motivated to expand the reach of their online audiences. Consistent with celebrity culture, heavy viewers are more likely to engage in promiscuous friending by agreeing to online relationships with relative strangers, and to engage in self promotion by sharing larger numbers of personal photographs with their audience.

Social cognitive theory provides a framework for understanding how viewers of RTV may enact specific behaviors online. Because RTV is hypothesized to model a specific set of attitudes and behaviors, viewing other categories of television content should not correlate with these behaviors. Thus, the following four hypotheses are proposed:

$\mathrm{H}_{1}$ : RTV consumption is positively related to time spent logged into SNS profiles.

$\mathrm{H}_{2}$ : RTV consumption is positively related to the size of users' online social networks.

$\mathrm{H}_{3}$ : RTV consumption is positively related to the proportion of users' online social networks who have never been met face to face (F2F).

$\mathrm{H}_{4}$ : RTV consumption is positively related to sharing photographs via SNSs.

\section{Methods}

\section{Pilot Study}

Since the dependent variables used in this study were single item measures, a pilot study was conducted to test the validity of these measures in terms of the accuracy of respondent recall. Two of the four dependent items were selected to test in the 
pilot study: the size of mediated networks, and the number of photographs shared. These items were chosen because exact, objective measurement of these variables is easily accessible by simply viewing online profiles. It is acknowledged that single item measures have the potential for attenuation. However when measures are in reference to precise, singular objects like the number of friends or the number of photos shared online, there is evidence that single items have comparable reliability and predictive validity as multiple item scales (Bergkvist \& Rossiter, 2007; Wanous \& Hudy, 2001).

One hundred students volunteered from an undergraduate class and were given research credit for participating in an online survey. Fifty three participants were female, and the entire group averaged 19.5 years $(S D=1.87)$ of age. For the recall data, participants reported an average of 259 network contacts $(S D=202)$ and an average of 84.4 photos shared $(S D=73.8)$. Pearson correlation coefficients between the recall and actual data were .64 and .61 for network size and number of photos shared, respectively.

To determine if systematic differences existed in recall based on age and gender, and to test how well recall data predicted actual data, two separate regression models were calculated. The model predicting network size was significant, $F(3$, $100)=33.15, p \leq .0001$; the recall variable was the only significant predictor $(\beta=$ $.61, p \leq .0001)$ of actual network size. Similarly, the regression model for number of photos shared was significant, $F(3,100)=29.05, p \leq .0001$, and the recall data was the only significant predictor $(\beta=.59, p \leq .0001)$. These results suggest that young people were able to recall the size of their online networks and the number of photos shared with a fair amount of accuracy, and no systematic differences were apparent in terms of age or gender.

\section{Main Study}

A total of 452 online surveys were completed by a sample of university students. This sample of participants was independent from the pilot study participants. Students were recruited from introductory communication classes and granted research credit for their participation, in accordance with Institutional Review Board protocols for student research involvement. Approximately $58 \%$ of the sample was female; the average age of participants was 20.3 years $(S D=2.6)$, thus participants did not significantly differ from pilot study participants in terms of demographic makeup. The majority of participants identified their ethnic background as Caucasian (approximately $62 \%$ ). About $16 \%$ were Asian, $6 \%$ were African-American, and $3 \%$ were Hispanic. The rest (about 13\%) identified with a variety of other ethnicities.

\section{Social Network Site Measures}

To measure the length of time spent logged into SNSs, participants were asked via an online survey "when you typically log into your SNS account, how many hours 
and minutes do you spend online." Participants reported spending an average of $47.4(S D=37.7)$ minutes per session. In general, two SNS users are either "friends," or they have no relationship whatsoever. This particular constraint is articulated by SNS platforms, and one question was used to measure how many "friends" participants are linked to via their SNSs. Participants reported an average of 282 friends $(S D=235)$.

Because of the likelihood that these friend connections do not accurately reflect the makeup of user's social networks, participants were also asked to estimate the number of these friend connections they have not actually met F2F. The average proportion of network contacts not met was $14 \%(S D=22)$. Finally, participants were asked to indicate the number of photographs of themselves they have publicly available on their SNS profiles $(M=71.6 ; S D=68.2)$.

Standard deviations for the SNS variables were higher than expected because the distributions of these variables were skewed to the right. However, consistent with McClendon (1994), these variables were not log transformed because regression models are robust when analyzing large sample sizes.

\section{Television Viewing Measures}

Television viewing was measured using a series of questions addressing five categories of content. Participants were asked "how many hours per day" and "how many days per week" they watched reality television, news, fiction, education, and "other" kinds of content. These items were consistent with Salomon and Cohen (1978) who suggest these measures were appropriate when measuring time spent viewing television. RTV consumption was prompted with examples like Real World and American Idol. Fiction shows were prompted with examples like The Simpsons, CSI, etc. Educational content was prompted with examples like The History Channel and The Discovery Channel. Overall, participants reported viewing approximately 32 hours of television weekly $(S D=27.8)$. On average, participants reported watching about 6 hours of reality television $(S D=9.6)$ and news $(S D=7.3)$ weekly, 9.3 hours of fiction $(S D=9.7)$, and 5.4 hours of educational programming $(S D=$ 7.3). The "other" category accounted for 4.7 hours weekly $(S D=7.1)$. Consistent with the SNS measures, the distributions of the television viewing variables were also skewed to the right, but were not transformed (McClendon, 1994).

\section{Results}

Table 1 summarizes the relationships between variables used in this study. Age was negatively correlated with time spent logged in SNSs, the number of friends participants report having connected to their profiles, and the number of photographs available online. Younger people seem to be investing the most resources into these tools. Network size and the proportion of friends not met were correlated with each 
Table 1

Descriptive Statistics and Zero-order Correlations for Variables; Means (Standard Deviations) Along the Diagonal

\begin{tabular}{|c|c|c|c|c|c|c|c|c|c|c|c|c|}
\hline & Age & Gender & $\begin{array}{c}\text { Time } \\
\text { Logged }\end{array}$ & $\begin{array}{c}\# \\
\text { Friends }\end{array}$ & $\begin{array}{c}\text { Prop } \\
\text { Not Met }\end{array}$ & Photos & RTV & News & Fiction & Edu & Other & All Tv \\
\hline Age & $20.3(2.7)$ & $0.10^{*}$ & $-0.16^{* *}$ & $-0.17^{* *}$ & 0.01 & $-0.18^{* * *}$ & -0.06 & 0.07 & 0.01 & $0.11^{*}$ & 0.01 & 0.03 \\
\hline Gender & & - & $-0.12^{*}$ & $-0.11^{*}$ & -0.07 & $-0.26^{* * *}$ & $-0.24^{* * *}$ & 0.08 & 0.02 & $0.22^{* * *}$ & $0.17^{* * *}$ & 0.06 \\
\hline Time logged in & & & $47.4(37.7)$ & $0.17^{* *}$ & $0.20^{* * *}$ & 0.08 & $0.22^{* * *}$ & 0.01 & 0.05 & 0.02 & $0.11^{*}$ & $0.11^{*}$ \\
\hline \# Friends on SNS & & & & $282(235)$ & $0.27^{* * *}$ & $0.47^{* * *}$ & $0.12 *$ & 0.04 & -0.02 & -0.01 & -0.09 & -0.01 \\
\hline Proportion not met & & & & & $.14(.22)$ & $0.18^{* * *}$ & $0.19^{* * *}$ & $0.12^{*}$ & 0.05 & $0.10^{*}$ & 0.05 & $0.15^{* *}$ \\
\hline \# Photos shared & & & & & & $71.6(68.2)$ & $0.11 *$ & -0.05 & -0.02 & -0.01 & $-0.11^{*}$ & -0.02 \\
\hline RTV hrs/wk & & & & & & & $6.1(8.5)$ & $0.26^{* * *}$ & $0.49^{* * *}$ & $0.24^{* * *}$ & $0.33^{* * *}$ & $0.70^{* * *}$ \\
\hline News hrs/wk & & & & & & & & $6.0(7.3)$ & $0.38^{* * *}$ & $0.38^{* * *}$ & $0.28^{* * *}$ & $0.61^{* * *}$ \\
\hline Fiction hrs/wk & & & & & & & & & $9.3(9.7)$ & $0.44^{* * *}$ & $0.44^{* * *}$ & $0.72^{* * *}$ \\
\hline Education hrs/wk & & & & & & & & & & $5.4(7.3)$ & $0.29 * * *$ & $0.64^{* * *}$ \\
\hline Other hrs/wk & & & & & & & & & & & $4.7(7.1)$ & $0.65^{* * *}$ \\
\hline All tv hrs/wk & & & & & & & & & & & & $31.28(27.8)$ \\
\hline
\end{tabular}


other, and the number of photographs available correlated with network size, as expected. Also expected was the strong correlation between all of the television viewing variables.

Ordinary least squares (OLS) regression was used to test the influence television viewing had on each of four dependent variables related to SNS use: time logged into SNSs, the size of participant social networks, the proportion of these networks not met, and the number of photographs shared on these sites. Table 2 summarizes the results from the four regression models.

In these models, age, gender, and aggregate television viewing were entered as independent variables and regressed onto the SNS measures to determine how television viewing affects each. This analysis began with aggregate television viewing to explore its influence before examining each category of television content separately. Aggregate television viewing $(\beta=.135)$ was a significant predictor of time spent logged into SNSs. Not surprisingly, younger participants spent more time managing their online profiles. Further, the more television participants watched, the more time they spent online.

In the next model, the size of participant's social networks was entered as the dependent variable. Although television viewing was not significant, younger people tended to have larger network sizes $(\beta=-.234)$. Age was the only significant predictor of network size, and this model explained about $4 \%$ of total variance.

When these variables were regressed onto the proportion of network contacts not met $\mathrm{F} 2 \mathrm{~F}$, only television viewing $(\beta=.148)$ was a significant predictor. As participants spent more time watching television, the likelihood that they would "friend" people they haven't actually met also increased. The last model summarized in Table 2 reveals that aggregate television consumption did not have a significant relationship with photo sharing. However, age $(\beta=-.288)$ and gender $(\beta=-.266)$ were both significant. Younger female participants share more photos on SNSs.

The next series of models presented in Table 3 were designed to explore the roles specific content categories of television play in terms of influencing online

Table 2

Standardized Beta Coefficients for Range of Dependent Variables, Aggregate TV Viewing

\begin{tabular}{lcccc}
\hline & $\begin{array}{c}\text { Time Logged } \\
\text { in, Session }\end{array}$ & $\begin{array}{c}\text { Size of SNS } \\
\text { Network }\end{array}$ & $\begin{array}{c}\text { \% not } \\
\text { met F2F }\end{array}$ & $\begin{array}{c}\text { Number } \\
\text { of Photos } \\
\text { Shared }\end{array}$ \\
\hline Age & -.072 & $-.234^{* * *}$ & 0.50 & $-.283^{* * *}$ \\
Gender & -.087 & -.097 & -.056 & $-.266^{* * *}$ \\
All TV viewing & $.135^{*}$ & -.033 & $.148^{* *}$ & -.016 \\
$F(3,449), \mathrm{R}^{2}$ & $6.21^{* * *}, .051$ & $4.73^{* *}, .037$ & $2.78^{* *}, .016$ & $16.17^{* * *}, .119$ \\
\hline
\end{tabular}

Note: ${ }^{*} p<.05 ;{ }^{* *} p<.01 ;{ }^{* *} p<.001 ;$ Female $=1$, Male $=2$. 
Table 3

Standardized Beta Coefficients for Range of Dependent Variables by TV Viewing Genre

\begin{tabular}{lcccc}
\hline & $\begin{array}{c}\text { Time } \\
\text { Logged in, } \\
\text { Daily }\end{array}$ & $\begin{array}{c}\text { Size of } \\
\text { Network }\end{array}$ & $\begin{array}{c}\text { \% not } \\
\text { met F2F }\end{array}$ & $\begin{array}{c}\text { Number of } \\
\text { Photos } \\
\text { Shared }\end{array}$ \\
\hline Age & -.077 & $-.240^{* * *}$ & 0.51 & $-.290^{* * *}$ \\
Gender & -.073 & -.063 & -.031 & $-.236^{* * *}$ \\
RTV hrs/week & $.183^{* *}$ & $.152^{*}$ & $.186^{* *}$ & $.107^{*}$ \\
News hrs/week & -.026 & .060 & .074 & -.041 \\
Fiction hrs/week & -.123 & -.130 & -.053 & -.060 \\
Education hrs/week & .059 & .037 & .046 & .073 \\
Other hrs/week & .097 & -.076 & -.038 & -.097 \\
$F(7,444), R^{2}$ & $4.02^{* * *}, .06$ & $3.56^{* * *}, .05$ & $2.40^{*}, .03$ & $9.33^{* * *}, .144$ \\
\hline
\end{tabular}

Note: ${ }^{*} p<.05 ;{ }^{* *} p<.01 ;{ }^{* * *} p<.001 ;$ Female $=1$, Male $=2$.

behavior and address the specific hypothesis outlined in this study. Five categories of television content were regressed onto the same four dependent variables constituting user behavior on SNSs in an effort to more clearly understand the relationship between television content and online behavior.

In the first model, the only variable that explained average time spent logged in to SNSs was frequency of RTV viewing ( $\beta=.183$ ). The model was significant $(F(7,444)=4.02, p \leq .001)$, and explained $6 \%$ of the variance, supporting the first hypothesis. RTV viewing was also significant $(\beta=.152)$ in the model predicting network size, as was age $(\beta=-.240)$, providing support for the second hypothesis. The addition of the content variables to this model strengthened the coefficient for age. Younger participants who watched RTV tended to have larger social network contacts via SNSs.

When the proportion of network contacts not met F2F was designated as dependent variable, only RTV viewing emerged as a significant predictor $(\beta=.186)$. Here, RTV viewing alone explained more variance in the model than aggregate television viewing in Table 2, resulting in support for the third hypothesis. The last model in Table 3 aimed to explain the frequency of photo sharing via SNSs. Again, RTV viewing was a significant predictor $(\beta=.107)$, which supports the fourth hypothesis. Consistent with earlier analyses, age $(\beta=-.290)$ and gender $(\beta=-.236)$ were also significant. RTV viewing was the only television viewing category significant in all four models; none of the other content categories were significant. Together, these results support all four hypotheses proposed.

To further highlight the trend in these analyses, Figure 1 was created to show the significance of RTV viewing in terms of each dependent variable. Because the measurement scales varied between these variables, the data was first standardized 
Figure 1

Differences Between Viewers and Non-Viewers of RTV

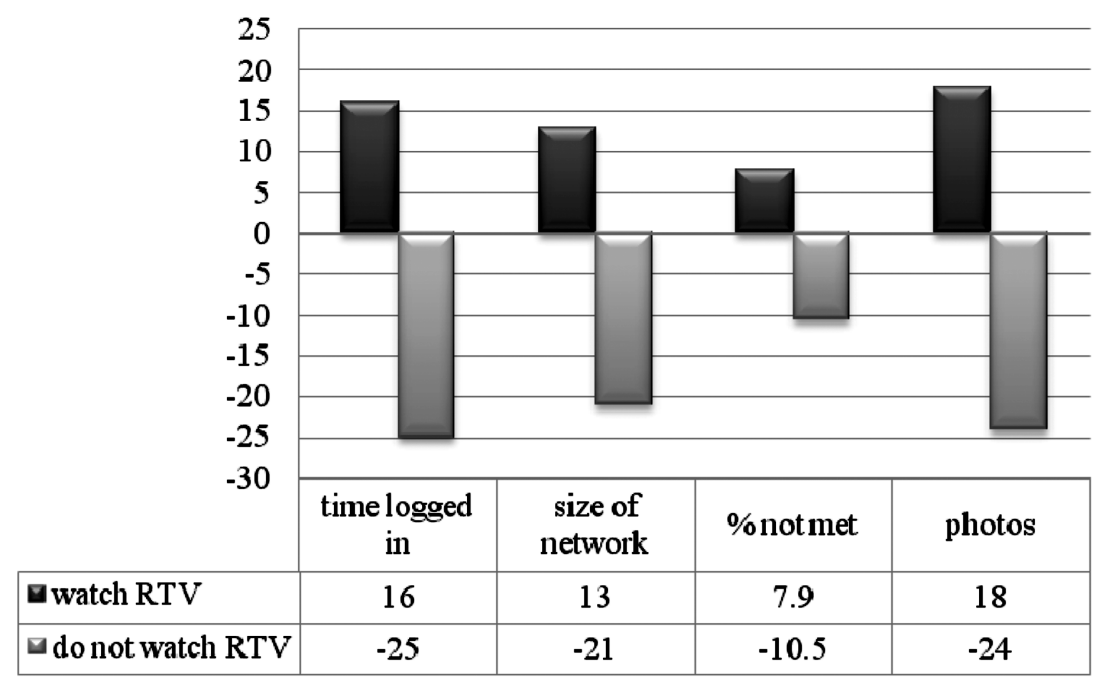

Note: Data have been standardized for comparison between variables.

before comparing differences in mean values for each. As Figure 1 shows, there were systematic differences between viewers and non-viewers of RTV in terms of the behavioral indices used in these analyses. ANOVA analyses confirm that the between group differences are all statistically significant at greater than $p \leq .01$.

Finally, post hoc power analyses based on Cohen's (1988) criteria were performed for each regression model. Except for the aggregate TV viewing model predicting the proportion of friends not met F2F (power $=.66$ ), all the models exceeded Cohen's minimum criterion of .8 .

\section{Discussion}

This research is founded on the premise that the confluence of the rising popularity of both RTV and Web 2.0 applications resulted in a shift regarding people's roles as media content consumers and producers. The purpose of this study was to explore the relationship between the increasing popularity of RTV and people's behavior on SNSs like Facebook. The evidence presented herein suggests that behavior traditionally associated with celebrities is being adopted en masse as people's interpersonal communication increasingly becomes mediated.

Utilizing social cognitive theory as the theoretical foundation, a positive relationship was expected between the amount of RTV young people consume and a range of online behavior in the context of SNSs including time spent logged 
in, online social network size, promiscuous friending, and the number of photos shared online. These behaviors were believed to reflect the systematic processing of messages and behavior broadly modeled within the genre of RTV. This study adds a unique perspective to people's motivations to participate with the social web, and several valuable insights were revealed.

First, aggregate television viewing was used in an attempt to explain the four dependent variables highlighting relevant user behavior on SNSs. The dependent variables used in these analyses represent a range of generalizable behaviors in which users regularly engage when using SNSs which correlate with behavior modeled in RTV programming. For example, if people believe that being the object of others' attention is positive (as portrayed by socially rewarding RTV), then they should be more likely to engage in promiscuous friending. Concomitantly, viewers of RTV also should be increasingly comfortable with digital images of themselves publicly available via the Internet, hence should share more photos via these sites. RTV viewing also should affect the length of time people spend online managing their profiles and the overall size of their networks.

Overall, respondents indicated they watched approximately 31 hours of television weekly, and exposure to television generally was a significant predictor of the time people spent logged into their SNS accounts. This evidence is consistent with Gerbner et al.'s (1986) cultivation theory which suggests heavy viewers of television come to believe the world is like the one portrayed on television, and that viewer's attitudes are shaped by and model those portrayed. Age was found to have a significant negative relationship with time spent logged in to SNSs. Freshmen and sophomores seem to be spending more time logged in to these sites, regardless of gender. This is consistent with recent findings by Ellison et al. (2007) who suggest that benefits may accrue to younger people by way of supplementing access to social capital. In part, television consumption explains user motivation for spending time online managing their social networks.

Although age had a strong negative relationship to the size of people's networks and the number of photos they shared, aggregate television viewing did not. Younger people clearly have larger SNS networks, but watching television did not impact this variable. However, when the percentage of network contacts not met was considered, results suggest that television viewing was influential. After controlling for the size of people's online networks, there was positive and significant relationship between the amount of television consumed and the likelihood that these network contacts are relative strangers. Extant research shows that people use networking sites to connect to others with whom they share an off line connection (Ellison et al., 2007). For example, students typically friend others with whom they have either shared a class, lived together, or otherwise met F2F. While this may often be the case, the results presented herein suggest that television viewing is associated with increased promiscuity in "friending" behavior online.

Aggregate television viewing did not have a significant relationship with photo sharing frequency. Age, gender, and education combined to explain the most variance (about $12 \%$ ) compared to the other three models, and younger female respon- 
dents were the most heavily engaged in this practice. Perhaps there are gender differences inherent in this behavior that should be considered in conjunction with media use. Although the findings in the current research begin to clarify the connection between RTV, the drive for celebrity, and SNSs, many questions remain. If stereotypical gender differences in bases of power persist online, then future research should address in greater detail women's motivations to share photos online.

Next, aggregate television viewing was parsed into 5 content categories, and these genres were then regressed onto the same four dependent variables used in the first set of analyses to further delineate the relative influence of each type of content. Television viewing was measured by prompting respondents to indicate how many hours per day and days per week they viewed RTV, news, fiction, educational and "other" kinds of programming. The results point to a consistent, positive, and significant relationship between RTV consumption and each of the dependent variables. In other words, exposure to RTV programming which models non-directed self-disclosure and positive outcomes associated with celebrity status had a strong and positive relationship with each of the dependent variables used in this study. It is also important to note that the lone RTV consumption variable explains more variance in every model than the aggregate viewing variable used in the first series of analyses.

This study links the consumption of a specific television genre with specific behavioral outcomes in new media. This represents a test and the development of social cognitive theory, and provides groundwork for future studies of television genre and audience behavior. The rapid adoption of online social media raised significant questions about personal privacy, the sociology of friendship and affiliation, and the changing role of the individual in the media system. The authors argue that these questions cannot be addressed without examining broader cultures of media use, which is a relatively novel proposal in contemporary studies of new media behavior. Although the models generally did not explain a great deal of variance (on average about $5.5 \%$ ), overall the models were highly significant. If one considers the multitude of media stimuli to which people are exposed day after day, it is not surprising that television viewing explains relatively small portions of behavior. This is consistent with extant research on media effects. While the evidence above suggests a moderate although significant relationship between traditional mass media use and behavior online, further research is needed to clarify this relationship. For example, it may be possible that voyeuristic people generally exhibit a preference for RTV consumption and SNS use.

Some limitations to this study lie in the broad conceptualization of messages communicated via RTV and the measurement of the dependent variables. Regardless of whether participants are vying for new romantic partners or trying to survive on tropical islands, the authors argue that these shows portray ordinary people as celebrities, and model this behavior for viewers. In this way, RTV generally communicates to viewers that celebrity is an attainable and good thing. Clearly there are a range of other messages communicated by RTV shows with differing 
content (for example, see Ferris et al., 2007), and these variables should continue to be studied in greater detail. Also, the dependent variables used in this study were measured with a single item, which raises issues regarding construct validity. The authors conducted a pilot study to explore people's ability to accurately recall basic SNS indices like the size of their network and the number of personal photos shared online. While random error did exist in the data, there was no evidence of nonrandom error in terms of age or gender biases. However, an objective measurement of time spent online and the proportion of friends not met F2F was not available, and questions remain about the validity of these two measures. Additional research is needed to address the accuracy of respondent recall to questions like these. Finally, measurement of participant engagement with RTV programming would have added explanatory power to the results. Such engagement could be measured by including assessment of whether or not participants watch RTV with their friends, or the extent to which participants manifest parasocial interaction or identification with RTV characters. Future research on the relationship between RTV and behavior would benefit from inclusion of these measures.

With the proliferation of SNSs and the aggregation and documentation of comprehensive "social networks," future research should address how the contemporary definition of "friend" is changing. One way to begin this investigation is to explore the utility and accessibility of resources embedded in SNS-mediated social networks. As the debate about whether Internet-based communication tools are enhancing social lives or restricting them continues (see McPherson, Smith-Lovin, \& Brashears, 2006, for recent discussion), additional research is needed to explore people's motivations to connect and ultimately whether these connects have instrumental utility for users.

\section{References}

Alexa. (2009). Alexa Top Sites. Retrieved March 20, 2009 from http://www.alexa.com/topsites. Bandura, A. (1986). Social foundations of thought and action: A social cognitive theory. Englewood Cliffs, NJ: Prentice-Hall.

Bandura, A. (2001). Social Cognitive Theory: An agentic perspective. Annual Review of Psychology, 52, 1-26.

Bandura, A., \& Walters, R. H. (1977). Social learning and personality development. London: Holt, Rinehart, and Winston.

Bente, G., \& Feist, A. (2000). Affect-Talk and its kin. In D. Zillman, \& P. Vorderer, (Eds.), Media entertainment: The psychology of its appeal (pp. 113-134). Mahwah, NJ: Lawrence Erlbaum Associates, Inc.

Bergkvist, L., \& Rossiter, J. R. (2007). The predictive validity of multiple-item versus single-item measures of the same constructs. Journal of Marketing Research, 44(2), 175-184.

boyd, d. (2006). Friends, friendsters, and Top 8: Writing community into being on social network sites. First Monday, 11(12). Retrieved March 20, 2009, from http://firstmonday.org/ issues/issue11_12/boyd/index.html

boyd, d., \& Heer, J. (2006). Profiles as conversation: Networked identity performance on Friendster. Proceedings of the Thirty-Ninth Hawai'i International Conference on System Sciences. Los Alamitos, CA: IEEE Press. 
Calvert, C. (2000). Voyeur nation: Media, privacy and peering in modern culture. Boulder, CO: Westview Press.

Choi, J. H. (2006). Living in Cyworld: Contextualising Cy-Ties in South Korea. In A. Bruns \& J. Jacobs (Eds.), Use of blogs (Digital Formations) (pp. 173-186). New York: Peter Lang.

Cohen, J. (1988). Statistical power analysis for the behavioral sciences (2nd ed.). Hillsdale, NJ: Lawrence Erlbaum Associates, Inc.

Dominick, J. R. (1984). Video games, television violence, and aggression in teenagers. Journal of Communication, 34(2), 136-147.

Ellison, N. B., Hineo, R., \& Gibbs, J. (2006). Managing impressions online: Self-presentation processes in the online dating environment. Journal of Computer-Mediated Communication, 11(2), 415-441.

Ellison, N. B., Steinfeld, C., \& Lampe, C. (2007). The benefits of Facebook "Friends": Social capital and college students' use of online social network sites. Journal of ComputerMediated Communication, 12(4), 1143-1168.

Ferris, A. L., Smith, S. W., Greenberg, B. S., \& Smith, S. L. (2007). The content of reality dating shows and viewer perceptions of dating. Journal of Communication, 57(3), 490-510.

Gerbner, G., Gross, L., Morgan, M., \& Signorielli, N. (1980). The "mainstreaming" of America: Violence profile no. 11. Journal of Communication, 30(3), 10-29.

Gerbner, G., Gross, L., Morgan, M., \& Signorielli, N. (1986). Living with television: The dynamics of the cultivation process. In J. Bryant \& D. Zillman (Eds.), Perspectives on media effects (pp. 17-40). Hillsdale, NJ: Lawrence Erlbaum Associates, Inc.

Gerbner, G., Gross, L., Signorielli, N., \& Morgan, M. (1980). Aging with television: Images on television drama and conceptions of social reality. Journal of Communication, 30(1), 3747.

Gross, G., Acquisti, A., \& Heinz, H. J. (2005). Information revelation and privacy in online social networks. In the Proceedings of the 2005 ACM workshop on Privacy in the electronic society. November, Alexandria, VA.

Hill, A. (2005). Reality TV: Audiences and popular factual television. New York: Routledge.

Lenhart, A., \& Madden, M. (2005). Teen content creators and consumers. Washington, DC: Pew Internet \& American Life Project. Retrieved March 20, 2009, from http://www.pew Internet.org/PPF/r/166/report_display.asp

McClendon, M. J. (1994). Multiple regression and casual analysis. Itasca, Illinois: Peacock.

McCraken, G. (1989). Who is the celebrity endorser? Cultural foundations of the endorsement process. Journal of Consumer Research, 16(3), 310-321.

McGhee, P. E., \& Frueh, T. (1980). Television viewing and the learning of sex-role stereotypes. Sex Roles, 6(2), 179-188.

McPherson, M., Smith-Lovin, L., \& Brashears, M. E. (2006). Social isolation in America: Changes in core discussion networks over two decades. American Sociological Review, $71(3), 353-375$.

Miller, A. D., \& Edwards, W. K. (2007). Give and take: A study of consumer photo-sharing culture and practice. In Proceedings of the SIGCHI Conference on human factors in computing systems (CHI '07). ACM, New York, NY, 347-356.

Morgan, M. (1982). Television and adolescents' sex-role stereotypes: A longitudinal study. Journal of Personality and Social Psychology, 43(5), 947-955.

O'Reilly, T. (2005). What is Web 2.0? Design patterns and business models for the next generation of software. Retrieved March 20, 2009, from http://www.oreillynet.com/pub/a/oreilly/ tim/news/2005/09/30/what-is-web-20.html

Profile of the American College Student (PACS) Survey (2007). Profile of the American College Student: University of Missouri-Columbia. Columbia, MO: Institutional Research, UMC. Retrieved March 20, 2009, from http://ir.missouri.edu/reports-presentations.html

Reiss, S., \& Wiltz, J. (2004). Why people watch reality TV. Media Psychology, 6(4), 363-378.

Rothschild, N. (1984). Small group affiliation as a mediating factor in the cultivation process. In G. Melischek, K. E. Rosengren, \& J. Stappers (Eds.) Cultural Indicators: An International Symposium (pp. 377-387). Vienna: Verlag der Osterreichischen Akademie der Wissenschaften. 
Rubin, A. M., Perse, E. M., \& Taylor, D. S. (1988). A methodological examination of cultivation. Communication Research, 15(2), 107-134.

Salomon, G., \& Cohen, A. A. (1978). On the meaning and validity of television viewing. Human Communication Research, 4(3), 256-270.

Shanahan, J., \& Morgan, M. (1999). Television and its viewers: Cultivation theory and research. Cambridge, UK: Cambridge University Press.

Shanahan, J., Scheufele, D. A., Yang, F., \& Hizi, S. (2004). Cultivation and spiral of silence effects: The case of smoking. Mass Communication \& Society, 7(4), 413-428.

Shrum, L. J. (2007). The implications of survey method for measuring cultivation effects. Human Communication Research, 33(1), 64-80.

Signorielli, N. (1990). Children, television, and gender roles: Messages and impact. Journal of Adolescent Health Care, 11(1), 50-58.

Stefanone, M. A., \& Jang, C. Y. (2007). Writing for Friends and Family: The Interpersonal Nature of Blogs. Journal of Computer-Mediated Communication, 13(1), 123-140.

Turkle, S. (1995). Life on the screen: Identity in the age of the Internet. New York: Simon and Schuster.

Walther, J. B. (2007). Selective self-presentation in computer-mediated communication: Hyperpersonal dimensions of technology, language, and cognition. Computers in Human Behavior, 23(5), 2538-2557.

Walther, J. B., Van Der Heide, B., Kim, S. Y., Westerman, D., \& Tong, S. Y. (2008). The role of friends' appearance and behavior on evaluations of individuals on Facebook: Are we known by the company we keep? Human Communication Research, 34(1), 28-49.

Wanous, J. P., \& Hudy, M. J. (2001). Single-item reliability: A replication and extension. Organizational Research Methods, 4(4), 361-375. 